\title{
ANALISIS KEPUASAN WISATAWAN TERHADAP ATRIBUT WISATA MENGGUNAKAN METODE CSI DAN IPA PADA WISATA PEMANDIAN DI KABUPATEN TAPANULI UTARA
}

\author{
Saula Lestari Tampubolon ${ }^{1)}$, Devis Wawan Saputra Simanjuntak ${ }^{2}$, \\ Mariana Simanjuntak ${ }^{3)}$ \\ ${ }^{123}$ Fakultas Teknologi Industri, Institut Teknologi Del \\ Email: saulatampubolon21@gmail.com,devis.saputra@gmail.com, lisbeth.anna@gmail.com
}

\begin{abstract}
Abstrak: Industri pariwisata ditetapkan sebagai salah satu sektor andalan dalam meningkatkan perekonomian karena perkembangannya yang pesat. Seiring dengan perkembangan tersebut diperlukan pula pengembangan secara konsisten salah satunya terhadap atribut produk wisata yang disediakan karena dipandang penting oleh konsumen dan dijadikan dasar pengambilan keputusan pembelian yang perlu diperhatikan oleh pengelola wisata. Pengelolaan atribut yang baik merupakan cara yang efektif dalam menarik minat konsumen dan dapat ditingkatkan dengan mengukur kepuasan wisatawan. Sumatera Utara salah satu provinsi yang paling sering menjadi destinasi wisata, dimana salah satu daerah wisatanya adalah Tapanuli Utara yang berpotensi besar menjadi wisata andalan dan wisata pemandian dinilai paling berpotensi. Terdapat tiga pemandian yang dinilai paling popular yaitu Pemandian Air Panas Sipoholon, Pemandian Air Soda dan Pemandian Air Panas Tamaro. Berdasarkan hal tersebut maka diperlukan perbaikan terhadap atribut wisata yang mencakup atraksi, amenitas, aksesibilitas dan ansilari yang berorientasi terhadap kepuasan wisatawan sehingga diperoleh prioritas perbaikan terhadap indikator yang ditentukan yang berdampak pada efisiensi wisata. Metode yang digunakan dalam penelitian ini adalah Metode Customer Satisfaction Index dan Importance Performance Analysis. Hasil dari penelitian diperoleh bawah nilai CSI sebesar 68,89\% yang termasuk dalam kategori puas dan melalui metode IPA diperoleh bahwa masih terdapat 8 atribut wisata yang memerlukan perbaikan prioritas.
\end{abstract}

Kata kunci: Proses keputusan pembelian, Customer Satisfaction Index, Importance Performance Analysis

\begin{abstract}
The tourism industrial is determined as one of the mainstay sector in improving the economy because of its rapid development. With that growing, need to consistently develop the tourism by the product attributes which is deemed important by consumers and used as basis for purchasing decision. Good management of attributes is one of the most effective ways of attracting consumers and to improve the quality can do by measure visitor satisfaction. North Sumatra is one of the most visited provinces as tourist destination, where North Tapanuli is one of its area which has great potentials to be developed into the mainstay tourism and bathing tourism is the most potentially rated tour. The most popular bathing are the Sipoholon, Tamaro Hot Spring and Air Soda. It is necessary to repair the tourism attributes that include attractions, amenities, accessibility and ansilary that are oriented towards the tourist satisfaction so that the priority is obtained indicators that have impacts on travel efficiency. The methods used in this research are the CSI and IPA methods. The result is obtained that CSI value of $68.89 \%$ which belongs to the satisfied category and using IPA method obtained that there are 8 attributes that maintain priority improvement.
\end{abstract}

Keywords: Purchasing decision process, Customer Satisfaction Index, Importance Performance Analysis

\section{PENDAHULUAN}

Industri pariwisata menjadi salah satu sektor industri andalan dalam meningkatkan perekonomian di Indonesia karena perkembangannya yang pesat dan terlihat dari kontribusinya terhadap devisa negara sudah mencapai $12 \%$ dari total 12 komoditas yang menjadi sumber devisa negara (Kemenpar, 2015). Pariwisata juga berperan penting dalam membuka lapangan pekerjaan bagi masyarakat di sekitar objek 
wisata yang dapat mengurangi pengangguran dan kemiskinan. Sehingga pengembangan secara konsisten terhadap pariwisata baik oleh pemerintah maupun oleh pengelola objek wisata sangat diperlukan. Salah satu caranya melalui pengingkatan kualitas atribut produk wisata Hal ini dikarenakan atribut produk dipandang penting oleh konsumen dan dijadikan dasar pengambilan keputusan pembelian yang perlu diperhatikan oleh perusahaan, serta pengelolaan yang baik merupakan salah satu cara paling efektif menarik minat konsumen dalam keputusan pembelian produk (Setyanto, Arifin, \& Sunarti, 2017).

Sumatera Utara adalah salah satu provinsi yang paling sering menjadi destinasi wisata bagi para wisatawan (Badan Pusat Statistika, 2017). Tapanuli Utara adalah salah satu daerah di Sumatera Utara yang berpotensi menjadi destinasi wisata andalan yang ditandai dengan peningkatan jumlah wisatawan sejak tahun 2014 yang mencapai 147.635 wisatawan dan memiliki 34 objek wisata. Beberapa diantaranya adalah pemandian air panas yang memiliki pemandangan bukit kapur yang indah serta pemandian air soda dengan warna kemerahan dan merupakan salah satu dari dua pemandian soda yang ada di dunia selain di Venezuela (Humas Sumut, 2018). Hal ini seharusnya menjadi kebanggaan bagi Tapanuli Utara dan mampu membuatnya menjadi wisata andalan. Kendala dalam meningkatkan sektor wisata Tapanuli Utara terletak pada keterbatasan ilmu pengetahuan pengelola wisata dalam mengelola objek wisata dan kurangnya kualitas pada atribut pariwisata. Atribut wisata dikategorikan oleh Cooper, et al (1995) menjadi empat yaitu atraksi, amenitas, aksesibilitas dan ansilari. Terdapat objek wisata Pemandian Ugan di Tapanuli Utara yang ditutup karena pengelolaan yang kurang memadai padahal memiliki potensi yang sama dengan pemandian lain menjadi bukti nyata hahwa kualitas atribut berpengaruh terhadap minat wisatawan berkunjung. Untuk itulah perlu adanya peran kedua pihak yaitu pemerintah dan pengelola wisata dalam pengembangan wisata dengan mengetahui atribut pariwisata yang perlu dan tidak perlu ditingkatkan agar pengelolaan objek wisata pemandian di Tapanuli Utara dapat lebih efisien. Oleh karena itu perlu dilakukan analisis terhadap kepuasan wisatawan terkait atribut wisata di wisata pemandian Kabupaten Tapanuli Utara, sehingga pemerintah dan pengelola wisata dapat mengetahui dan melakukan perbaikan dan peningkatan terhadap objek wisata yang akan berdampak pada peningkatan jumlah wisatawan secara merata di keseluruhan objek wisata pemandian di Tapanuli Utara. Apabila dirangkum, penelitian ini bertujuan untuk mengetahui perilaku dan proses pengambilan keputusan konsumen dalam memilih destinasi wisata pemandian, melakukan analisis kepuasan wisatawan terhadap atribut wisata dan memberi rekomendasi alternatif kebijakan dalam mengembangkan wisata pemandian di Kabupaten Tapanuli Utara.

\section{METODE PENELITIAN}

\section{Kerangka Penelitian}

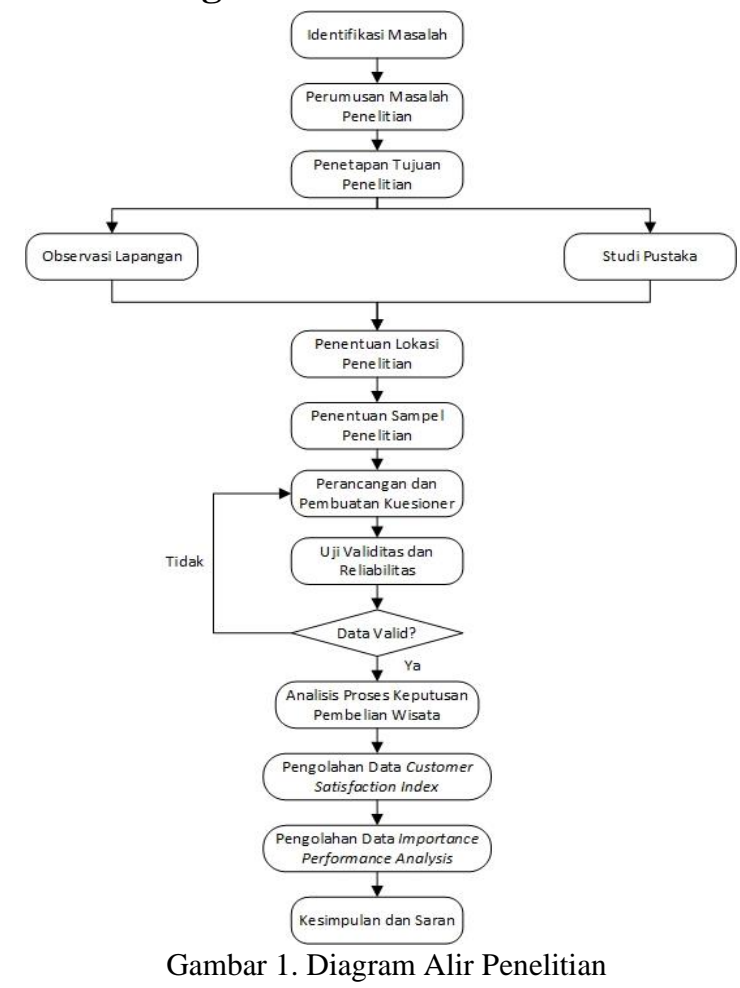


2. Objek dan Teknik Sampel Penelitian

Objek penelitian ini adalah Pemandian Air Panas Sipoholon, Pemandian Air Soda dan Pemandian Air Panas Tamaro. Populasi dalam penelitian ini mengacu pada jumlah wisatawan nusantara di Kabupaten Tapanuli Utara pada tahun 2017 yaitu 145.765 wisatawan. Teknik sampel yang digunakan adalah accidental sampling Jumlah sampel dalam penelitian ditentukan menggunakan rumus Slovin, yaitu:

$$
n=\frac{N}{N\left(d^{2}\right)+1}
$$

Keterangan:

$\mathrm{n}=$ Jumlah sampel

$\mathrm{N}=$ Jumlah populasi

$\mathrm{d}=$ Presisi (Toleransi ketidakpastian)

$$
\begin{gathered}
n=\frac{N}{N\left(d^{2}\right)+1} \\
n=\frac{145.765}{145.765\left(0,05^{2}\right)+1} \\
n=\frac{145.765}{365,4125} \\
n=398,90=399
\end{gathered}
$$

\section{Teknik Pengumpulan Data dan Definisi Operasional Variabel}

Teknik pengumpulan data dilakukan dengan tiga cara yaitu studi literatur, observasi dan kuesioner. Pada penelitian ini, terdapat 3 bagian definisi operasional variabel penelitian yaitu:

a. Karakteristik wisatawan, yang terdiri dari usia, tempat tinggal, uang saku/penghasilan serta pekerjaan wisatawan

b. Proses keputusan pembelian yang terdiri dari 5 tahap yakni pengenalan kebutuhan, pencarian informasi, evaluasi alternatif, pengambilan keputusan dan perilaku setelah pembelian.

c. Produk wisata yang terdiri dari 4 aspek yakni atraksi, amenitas, aksesibilitas dan ansilari. Atribut yang dinilai dari 4 aspek tersebut dapat dilihat pada tabel di bawah ini.
Tabel 1. Definisi Operasional Variabel Produk Wisata

\begin{tabular}{|l|l|}
\hline No & \multicolumn{2}{|c|}{ Indikator } \\
\hline ATRAKSI \\
\hline A1 & Keindahan pemandangan alam \\
\hline A2 & Memiliki manfaat kesehatan \\
\hline A3 & Perasaan relaksasi setelah kunjungan \\
\hline A4 & $\begin{array}{l}\text { Pengelolaan tempat wisata untuk spot } \\
\text { foto }\end{array}$ \\
\hline AMENITAS \\
\hline A5 & $\begin{array}{l}\text { Tersedia restoran/warung makan/ } \\
\text { rumah makan }\end{array}$ \\
\hline A6 & Pelayanan pegawai \\
\hline A7 & Cita rasa makanan \\
\hline A8 & Kesesuaian tingkat harga makanan \\
\hline A9 & Terdapat toko souvenir/ cenderamata \\
\hline A10 & $\begin{array}{l}\text { Tersedia penginapan/hotel di sekitar } \\
\text { lokasi wisata }\end{array}$ \\
\hline A11 & Kesesuaian tingkat harga penginapan \\
\hline A12 & Tersedia lahan parkir yang memadai \\
\hline A13 & Keamanan tempat parkir \\
\hline A14 & Tersedia jumlah toilet yang memadai \\
\hline A15 & Toilet yang bersih \\
\hline A16 & $\begin{array}{l}\text { Pengelolaan dan tata letak komponen } \\
\text { wisata yang baik }\end{array}$ \\
\hline A17 & $\begin{array}{l}\text { Tersedia tempat sampah yang } \\
\text { memadai }\end{array}$ \\
\hline A18 & $\begin{array}{l}\text { Terdapat rambu-rambu keamanan } \\
\text { pada objek wisata }\end{array}$ \\
\hline AKSESIBILITAS \\
\hline A19 & Kondisi jalan menuju tempat wisata \\
\hline A20 & $\begin{array}{l}\text { Tersedia transportasi umum menuju } \\
\text { lokasi wisata }\end{array}$ \\
\hline A21 & $\begin{array}{l}\text { Jumlah transportasi umum yang } \\
\text { memadai menuju lokasi wisata }\end{array}$ \\
\hline A22 & $\begin{array}{l}\text { Jarak menuju lokasi wisata dari pusat } \\
\text { kota }\end{array}$ \\
\hline A23 & $\begin{array}{l}\text { Jarak penginapan/hotel dari lokasi } \\
\text { wisata }\end{array}$ \\
\hline A24 & $\begin{array}{l}\text { Tersedia penunjuk arah menuju } \\
\text { lokasi wisata }\end{array}$ \\
\hline ANSILARI \\
\hline A25 & $\begin{array}{l}\text { Terdapat Bank/ATM di sekitar wisata } \\
\text { wan araknya terjangkau }\end{array}$ \\
\hline A26 & Keramahtamahan warga sekitar objek \\
\hline
\end{tabular}

\section{Metode Analisis Data}

4.1 Metode Deskriptif dan Pendekatan

Kuantitatif

Menurut Suryana dalam (Pangaribuan, 2018) metode deskriptif digunakan untuk 
mencari unsur-unsur, ciri-ciri, sifa-sifat suatu fenomena yang dimana dalam pelaksanaannya dilakukan melalui teknik survei. Sedangkan, pendekatan kuantitatif maksudnya pengumpulan data-data yang akan diolah berupa angka-angka.

\subsection{Metode Customer Satisfaction Index}

Lerbin Aritonang mengatakan CSI dapat digunakan untuk mengukur tingkat kepuasan seseorang terhadap suatu produk/jasa. Metode CSI memiliki 5 tahap yaitu sebagai berikut:

a. Menentukan Mean Importance Score (MIS) dan Mean Satisfaction Score (MSS)

MIS adalah rata-rata kepentingan dan MSS adalah kepuasan setiap responden. Rumus:

$$
\begin{array}{ll}
\bar{Y}=\text { MIS } & \bar{X}=\text { MSS } \\
=\frac{\sum_{\mathrm{i}=1}^{\mathrm{Y}} \mathrm{Yi}}{\mathrm{n}} & =\frac{\sum_{\mathrm{i}=1}^{\mathrm{X}} \mathrm{Xi}}{\mathrm{n}}
\end{array}
$$

Keterangan:

$Y i=$ Nilai kepentingan atribut ke $\mathrm{i}$

$X i=$ Nilai kepuasan ke $\mathrm{i}$

$n$ = Jumlah konsumen/responden

b. Membuat Weight Factor (WF)

WF yaitu bobot presentasi nilai MIS per atribut terhadap total MIS seluruh atribut, dengan rumus:

$$
W F=\frac{M I S i}{\sum_{i=1}^{k} M I S i}
$$

Keterangan:

$\mathrm{k}=$ Atribut kepentingan ke $\mathrm{k}$

c. Membuat Weight Score (WS)

WS merupakan bobot perkalian antara WF dengan rata-rata tingkat kepuasan masingmasing atribut atau MSS

$$
W S i=W F i x M S S i
$$

\section{d. Menentukan skala CSI}

Skala kepuasan konsumen yang umum dipakai dalam interpretasi indeks adalah skala 0 sampai 1 atau nol sampai seratus.

$$
C S=\frac{\sum_{i=1}^{n} W S i}{H S} \times 100 \%
$$

Keterangan:
HS = High Scaled (jumlah skala yang digunakan saat penelitian yaitu 5)

Tabel 2. Kriteria Penilaian CSI

\begin{tabular}{|l|l|}
\hline Nilai CSI & Kriteria CSI \\
\hline$>0,81$ & Sangat Puas \\
\hline $0,66-0,80$ & Puas \\
\hline $0,51-0,65$ & Cukup Puas \\
\hline $0,35-0,50$ & Kurang Puas \\
\hline $0,00-0,34$ & Tidak Puas \\
\hline
\end{tabular}

Sumber: Panduan survey Kepuasan

Konsumen PT. SUCOFINDO 2004

\subsection{Metode Importance Performance Analysis}

Metode IPA digunakan untuk memetakan hubungan antara kepentingan dengan kinerja setiap atribut yang ditawarkan. Kuesioner merupakan instrumen utama yang akan digunakan dalam metode IPA, Tingkat kepentingan dan tingkat kinerja diukur dengan menggunakan pembobotan skala likert yang memilliki skala 1 sampai 5 dengan penjelasan sebagai berikut:

1. Variabel Tingkat Kepentingan (Y)

Tabel 3. Skala Tingkat Kepentingan

\begin{tabular}{|l|c|}
\hline \multicolumn{1}{|c|}{ Jawaban } & Skala/Bobot \\
\hline Jawaban Sangat Penting & 5 \\
\hline Jawaban Penting & 4 \\
\hline Jawaban Cukup Penting & 3 \\
\hline Jawaban Kurang Penting & 2 \\
\hline Jawaban Tidak Penting & 1 \\
\hline
\end{tabular}

2. Variabel Tingkat Kinerja (X)

Tabel 4. Skala Tingkat Kepuasan

\begin{tabular}{|l|c|l|}
\hline \multicolumn{1}{|c|}{ Jawaban } & $\begin{array}{c}\text { Skala/ } \\
\text { Bobot }\end{array}$ & \multicolumn{1}{|c|}{ Keterangan } \\
\hline $\begin{array}{l}\text { Jawaban } \\
\text { Sangat Penting }\end{array}$ & 5 & $\begin{array}{l}\text { Wisatawan } \\
\text { Sangat Puas }\end{array}$ \\
\hline $\begin{array}{l}\text { Jawaban } \\
\text { Penting }\end{array}$ & 4 & $\begin{array}{l}\text { Wisatawan } \\
\text { Puas }\end{array}$ \\
\hline $\begin{array}{l}\text { Jawaban Cukup } \\
\text { Penting }\end{array}$ & 3 & $\begin{array}{l}\text { Wisatawan } \\
\text { Cukup Puas }\end{array}$ \\
\hline $\begin{array}{l}\text { Jawaban } \\
\text { Kurang Penting }\end{array}$ & 2 & $\begin{array}{l}\text { Wisatawan } \\
\text { Kurang Puas }\end{array}$ \\
\hline $\begin{array}{l}\text { Jawaban Tidak } \\
\text { Penting }\end{array}$ & 1 & $\begin{array}{l}\text { Wisatawan } \\
\text { Tidak Puas }\end{array}$ \\
\hline
\end{tabular}

Tahapan pengerjaan metode ini menurut Supranto, J dalam (Kurniawati, Santoso, \& Iksan, 2014) adalah sebagai berikut: 
a. Menentukan tingkat kesesuaian antara tingkat kepentingan dan tingkat kinerja Tingkat kesesuaian untuk menentukan urutan prioritas peningkatan faktor yang dapat mempengaruhi kualitas pelayanan. Dengan rumus sebagai berikut:

Keterangan:

$$
T_{k i}=\frac{X i}{Y i} \times 100 \%
$$

$T_{k i}=$ Tingkat kesesuaian responden

$X=$ Skor penilaian pelaksanaan kinerja penyedia jasa

$Y=$ Skor penilaian kepentingan pengguna jasa

b. Menentukan skor rata-rata tingkat kinerja dan tingkat kepentingan

$$
\overline{X_{l}}=\frac{\sum_{\mathrm{i}=1}^{\mathrm{k}} \mathrm{Xi}}{\mathrm{n}} \quad \overline{\mathrm{Y}}_{\mathrm{l}}=\frac{\sum_{\mathrm{i}=1}^{\mathrm{k}} \mathrm{Yi}}{\mathrm{n}}
$$

Keterangan:

$\overline{X \imath}=$ Skor rata-rata tingkat penilaian atribut kinerja ke-i

$\bar{Y} \iota=$ Skor rata-rata tingkat penilaian atribut kepentingan/harapan ke-i

$n=$ Jumlah responden

c. Menentukan rata-rata kinerja dan kepentingan keseluruhan atribut

Hubungan antara tingkat kepuasan (kinerja) dan tingkat kepentingan ditentukan dengan menggunakan diagram kartesius. Rumus untuk memperoleh titik $\mathrm{x}$ dan $\mathrm{y}$ pada diagram kartesius:

$$
\overline{\bar{X}}=\frac{\sum_{\mathrm{i}=1}^{\mathrm{k}} \overline{\mathrm{X}} \mathrm{l}}{\mathrm{n}} \quad \overline{\overline{\mathrm{Y}}}=\frac{\sum_{\mathrm{i}=1}^{\mathrm{k}} \overline{\mathrm{Y}}_{1}}{\mathrm{n}}
$$

Keterangan:

$\bar{X}=$ Skor rata-rata tingkat penilaian kinerja seluruh atribut

$\bar{Y}=$ Skor rata-rata tingkat penilaian kepentingan/harapan seluruh atribut $\mathrm{K}=$ Banyaknya atribut yang dapat mempengaruhi kepuasan wisatawan

d. Memetakan ke dalam diagram kartesius Ketentuan kuadran pada diagram adalah sebagai berikut:

1. Kuadran A (prioritas utama), bila atribut memiliki nilai $\overline{X l}<\overline{\bar{X}}$ dan nilai $\bar{Y} \iota>\overline{\bar{Y}}$
2. Kuadran B (pertahankan prestasi), bila nilai $\overline{X \imath}>\overline{\bar{X}}$ dan nilai $\bar{Y} \iota>\overline{\bar{Y}}$

3. Kuadran $\mathrm{C}$ (prioritas rendah) bila atribut tersebut memiliki nilai $\bar{X} \iota \overline{\bar{X}}$ dan nilai $\bar{Y} l<\overline{\bar{Y}}$

4. Kuadran D (berlebihan) bila atribut tersebut memiliki nilai $\bar{X} \iota>\overline{\bar{X}}$ dan nilai $\overline{Y_{l}}<\overline{\bar{Y}}$

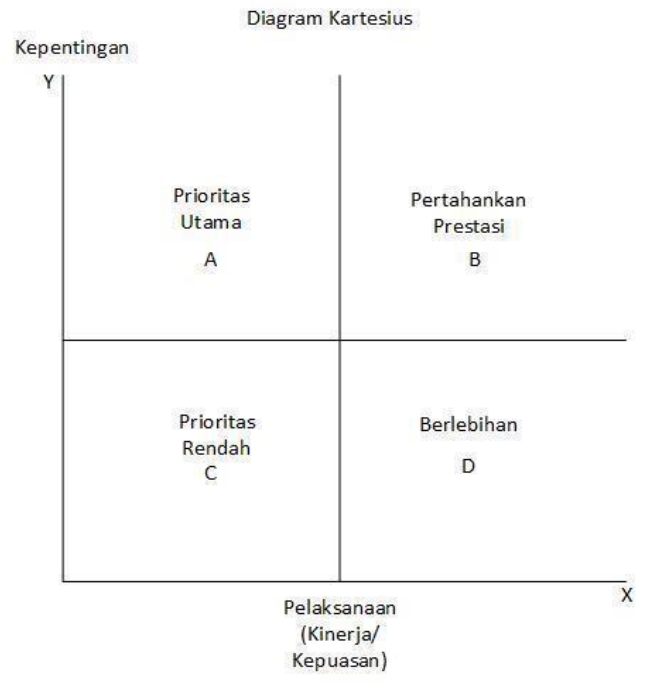

Sumber : (Martilla \& James, 1977)

Gambar 2. Diagram Kartesius

\section{HASIL DAN PEMBAHASAN}

\section{Karakteristik Wisatawan}

\subsection{Jenis Kelamin}

Berdasarkan hasil penelitian, dari keseluruhan wisatawan yang menjadi responden, sebesar 55\% pengunjung adalah wanita, sisanya $45 \%$ adalah pria.

\subsection{Usia}

Berdasarkan hasil penelitian diperoleh bahwa wisatawan dengan proporsi usia terbesar adalah 17-25 tahun sebesar 47\%, 26-35 tahun sebesar 22\%, 36-45 tahun $15 \%$, 46-55 tahun $10 \%$ dan lebih dari 55 tahun $6 \%$. Bisa disimpulkan semakin muda usia maka kemungkinan untuk melakukan wisata semakin tinggi.

\subsection{Kota Tempat Tinggal}

Untuk asal kota tepat tinggal, didominasi oleh wisatawan yang berasal dari luar Tapanuli Utara sebesar 60\%, dan 40\% dari Tapanuli Utara. 


\subsection{Pekerjaan}

Wisatawan yang mendominasi kunjungan adalah pelajar/mahasiswa yaitu sebesar $35 \%$, diikuti dengan pegawai swasta $24 \%$, wiraswasta $21 \%$, lainnya $12 \%$ dan PNS $8 \%$. Jumlah pelajar/mahasiswa yang besar juga sesuai dengan usia pengunjung sebelumnya yang didominasi oleh usia 17-25 tahun.

1.5 Penghasilan/Uang Saku

Hasil penelitian terhadap penghasilan/uang saku pengunjung, penelitian menunjukkan penghasilan didominasi oleh rentang lebih kecil dari 1 juta yakni 34\%, diikuti rentang 2 sampai 3 juta $26 \%$, dan seterusnya.

\section{Proses Keputusan Pembelian}

2.1 Pengenalan Kebutuhan

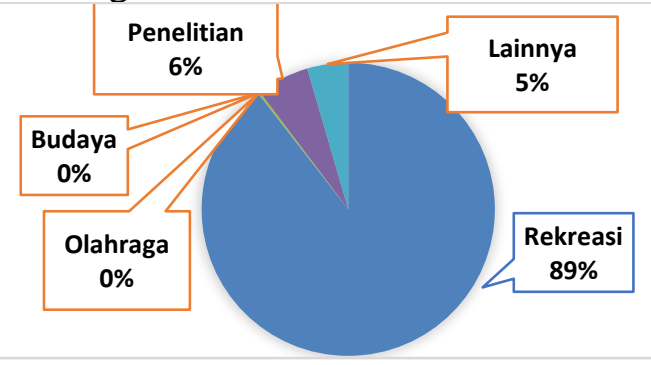

Gambar 3. Motivasi/Alasan Wisatawan dalam Berkunjung

2.2 Pencarian Informasi

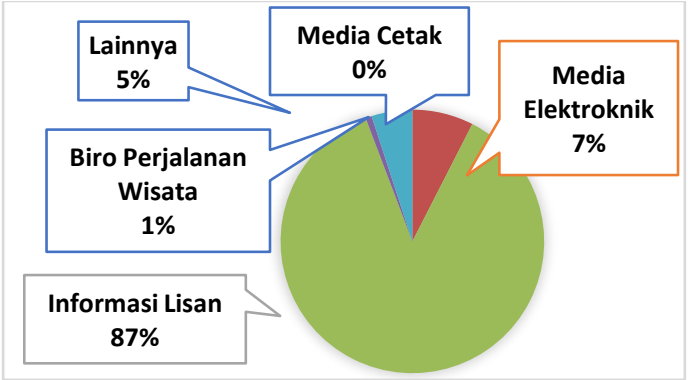

Gambar 4. Sumber Informasi wisatawan dalam Berkunjung

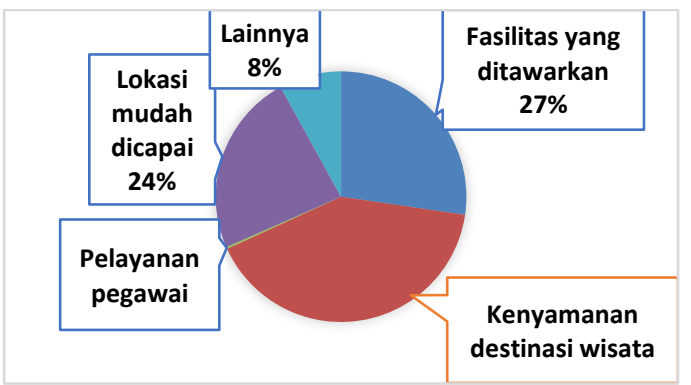

Gambar 5. Fokus Utama dari Informasi yang diperoleh

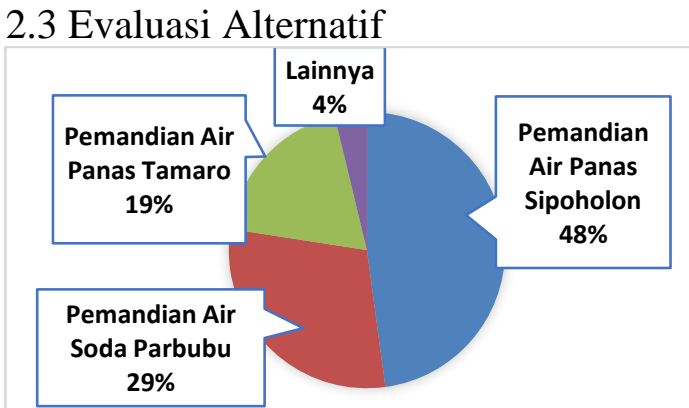

Gambar 6. Evaluasi Pemilihan Tempat Wisata

Faktor lain yang perlu dipertimbangkan agar dapat menarik wisatawan berkunjung.

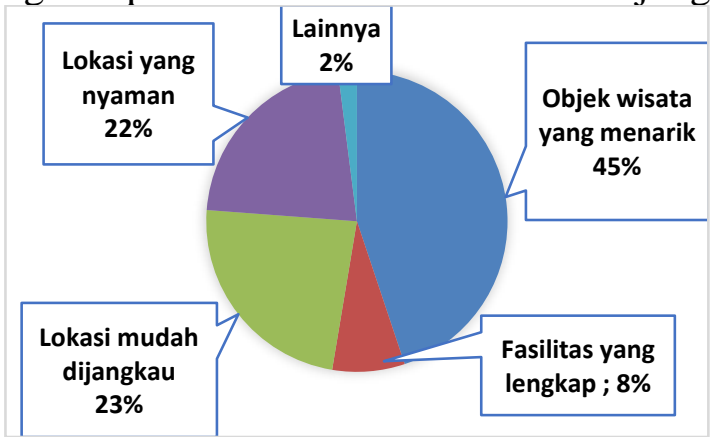

Gambar 7. Hal yang dipertimbangkan dari objek wisata

\subsection{Keputusan Pembelian}

a. Waktu Berkunjung

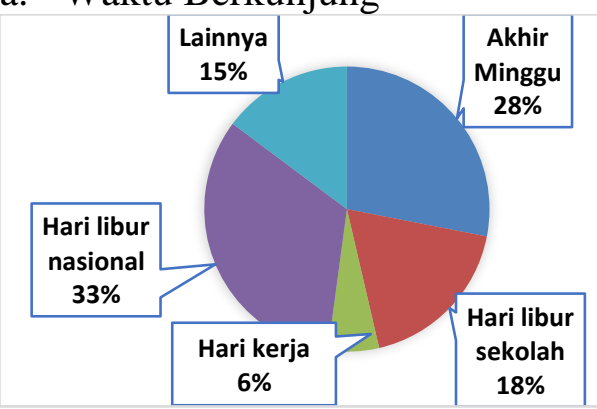

Gambar 83. Keputusan Waktu Berkunjung

b. Teman Berkunjung

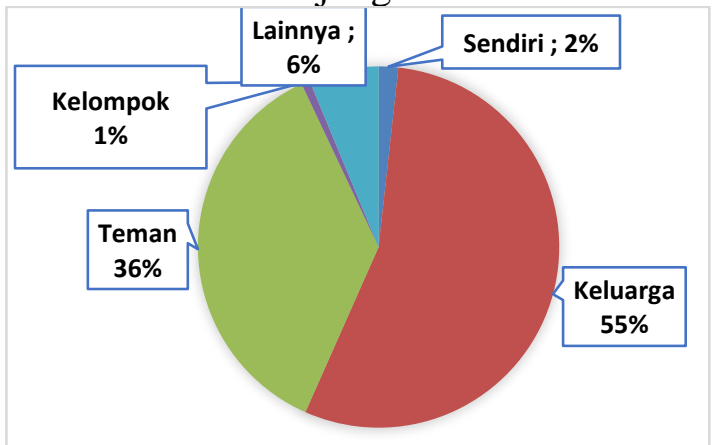

Gambar 9. Teman Berkunjung 
c. Cara Memutuskan Kunjungan

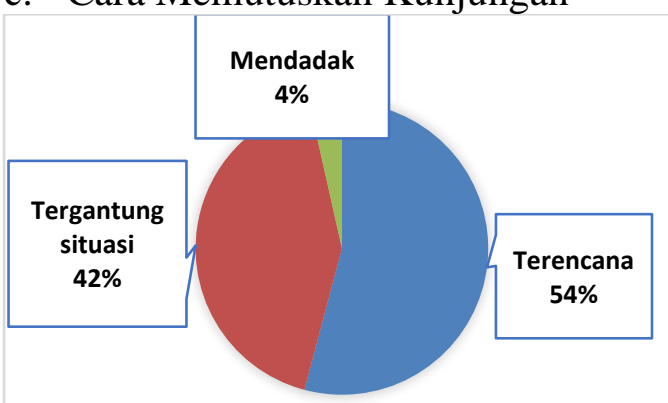

Gambar 4. Cara Memutuskan Kunjungan

2.5 Evaluasi Perilaku Setelah Pembelian

a. Kepuasan Wissatawan

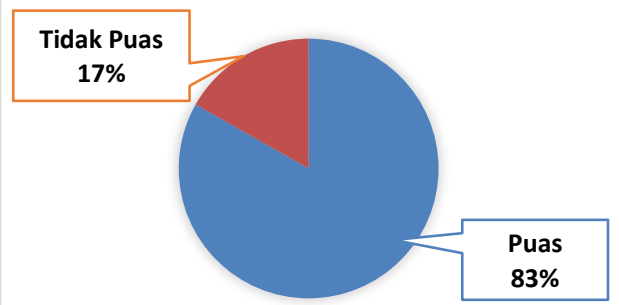

Gambar 5. Kepuasan Wisatawan

b. Minat Berkunjung Kembali

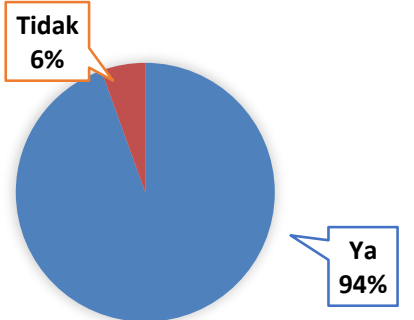

Gambar 6. Minat Berkunjung Kembali

c. Frekuensi Berkunjung ke Wisata Pemandian Tapanuli Utara

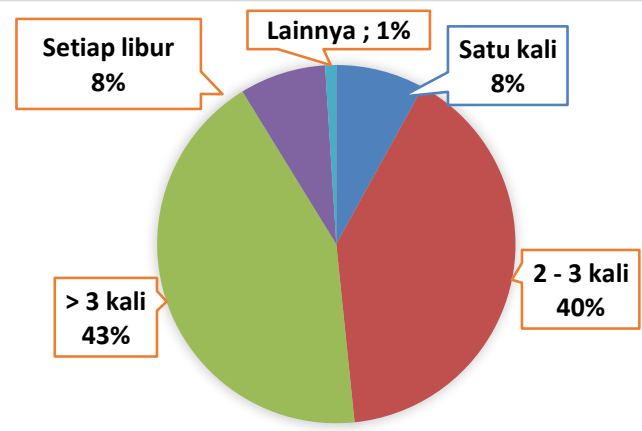

Gambar 7. Berkunjung ke Wisata Pemandian Tapanuli Utara

\section{Analisi Kepuasan Wisatawan}

\subsection{Customer Satisfaction Index (CSI)}

Tabel 5. Hasil Perhitungan Customer Satisfaction Index

\begin{tabular}{|l|l|c|c|c|c|}
\hline No & \multicolumn{1}{|c|}{ Indikator } & MIS & MSS & WF (\%) & WS \\
\hline A1 & Keindahan pemandangan alam & 4,37 & 3,59 & $3,90 \%$ & 0,140018 \\
\hline A2 & Memiliki manfaat kesehatan & 4,51 & 3,97 & $4,03 \%$ & 0,159933 \\
\hline A3 & Perasaan relaksasi setelah kunjungan & 4,38 & 3,96 & $3,91 \%$ & 0,155030 \\
\hline A4 & Pengelolaan tempat wisata untuk spot foto & 4,33 & 3,08 & $3,87 \%$ & 0,118941 \\
\hline A5 & $\begin{array}{l}\text { Tersedia restoran/warung makan/ rumah } \\
\text { makan }\end{array}$ & 4,64 & 3,74 & $4,15 \%$ & 0,155215 \\
\hline A6 & Pelayanan pegawai & 4,39 & 3,17 & $3,92 \%$ & 0,124328 \\
\hline A7 & Cita rasa makanan & 4,34 & 3,22 & $3,88 \%$ & 0,124729 \\
\hline A8 & Kesesuaian tingkat harga makanan & 4,02 & 3,38 & $3,59 \%$ & 0,121383 \\
\hline A9 & Terdapat toko souvenir/ cenderamata & 3,55 & 3,26 & $3,17 \%$ & 0,103271 \\
\hline A10 & $\begin{array}{l}\text { Tersedia penginapan/hotel di sekitar lokasi } \\
\text { wisata }\end{array}$ & 3,72 & 3,42 & $3,32 \%$ & 0,113468 \\
\hline A11 & Kesesuaian tingkat harga penginapan & 3,81 & 3,43 & $3,40 \%$ & 0,116740 \\
\hline A12 & Tersedia lahan parkir yang memadai & 4,51 & 3,17 & $4,03 \%$ & 0,127603 \\
\hline A13 & Keamanan tempat parkir & 4,69 & 3,99 & $4,19 \%$ & 0,167272 \\
\hline A14 & $\begin{array}{l}\text { Tersedia jumlah kamar mandi/toilet yang } \\
\text { memadai }\end{array}$ & 4,68 & 3,48 & $4,18 \%$ & 0,145631 \\
\hline A15 & Toilet yang bersih & 4,65 & 3,27 & $4,16 \%$ & 0,135737 \\
\hline A16 & $\begin{array}{l}\text { Pengelolaan dan tata letak komponen wisata } \\
\text { yang baik }\end{array}$ & 4,54 & 3,21 & $4,05 \%$ & 0,129865 \\
\hline A17 & $\begin{array}{l}\text { Tersedia tempat sampah yang memadai di } \\
\text { kamar mandi dan sekitar lokasi wisata }\end{array}$ & 4,44 & 3,38 & $3,96 \%$ & 0,133747 \\
\hline
\end{tabular}




\begin{tabular}{|c|l|c|c|c|c|}
\hline No & \multicolumn{1}{|c|}{ Indikator } & MIS & MSS & WF (\%) & WS \\
\hline A18 & $\begin{array}{l}\text { Terdapat rambu-rambu keamanan pada } \\
\text { objek wisata }\end{array}$ & 4,06 & 2,99 & $3,62 \%$ & 0,108260 \\
\hline A19 & Kondisi jalan menuju tempat wisata & 4,50 & 3,12 & $4,02 \%$ & 0,125606 \\
\hline A20 & $\begin{array}{l}\text { Tersedia transportasi umum menuju lokasi } \\
\text { wisata }\end{array}$ & 4,42 & 3,46 & $3,95 \%$ & 0,136383 \\
\hline A21 & $\begin{array}{l}\text { Jumlah transportasi umum yang memadai } \\
\text { menuju lokasi wisata }\end{array}$ & 4,25 & 3,22 & $3,79 \%$ & 0,122280 \\
\hline A22 & Jarak menuju lokasi wisata dari pusat kota & 3,94 & 3,56 & $3,52 \%$ & 0,125143 \\
\hline A23 & Jarak penginapan/hotel dari lokasi wisata & 4,15 & 3,58 & $3,71 \%$ & 0,132831 \\
\hline A24 & $\begin{array}{l}\text { Tersedia penunjuk arah menuju lokasi } \\
\text { wisata }\end{array}$ & 4,47 & 3,59 & $4,00 \%$ & 0,143592 \\
\hline A25 & $\begin{array}{l}\text { Terdapat Bank/ATM di sekitar wisata dan } \\
\text { araknya terjangkau }\end{array}$ & 4,28 & 3,52 & $3,82 \%$ & 0,134462 \\
\hline A26 & Keramahtamahan warga sekitar objek wisata & 4,32 & 3,70 & $3,86 \%$ & 0,143023 \\
\hline Total & 111,97 & 89,45 & 3,444490 \\
\hline
\end{tabular}

Nilai CSI adalah $68,89 \%$, berada pada rentang $0.66 \%-0.80 \%$, artinya wisatawan sudah merasa puas terhadap atribut yang diukur tingkat kepuasannya. Meskipun begitu, masih tetap terdapat

\subsection{Importance Performance Analysis}

a. Tingkat Kesesuaian Kinerja terhadap Kepentingan

Tabel 6. Tingkat Kesesuaian Atribut Wisata Pemandian di Tapanuli Utara

\begin{tabular}{|l|l|c|c|c|}
\hline No & \multicolumn{1}{|c|}{ Indikator } & $\begin{array}{c}\text { Penilaian } \\
\text { Kinerja } \\
(\mathrm{X})\end{array}$ & $\begin{array}{c}\text { Penilaian } \\
\text { Kepentingan } \\
(\mathrm{Y})\end{array}$ & Tki (\%) \\
\hline A1 & Keindahan pemandangan alam & 1432 & 1743 & $82,16 \%$ \\
\hline A2 & Memiliki manfaat kesehatan & 1583 & 1801 & $87,90 \%$ \\
\hline A3 & Perasaan relaksasi setelah kunjungan & 1581 & 1748 & $90,45 \%$ \\
\hline A4 & Pengelolaan tempat wisata untuk spot foto & 1227 & 1728 & $71,01 \%$ \\
\hline A5 & Tersedia restoran/warung makan/ rumah makan & 1494 & 1852 & $80,67 \%$ \\
\hline A6 & Pelayanan pegawai & 1265 & 1752 & $72,20 \%$ \\
\hline A7 & Cita rasa makanan & 1283 & 1733 & $74,03 \%$ \\
\hline A8 & Kesesuaian tingkat harga makanan & 1349 & 1604 & $84,10 \%$ \\
\hline A9 & Terdapat toko souvenir/ cenderamata & 1301 & 1415 & $91,94 \%$ \\
\hline A10 & Tersedia penginapan/hotel di sekitar lokasi wisata & 1363 & 1484 & $91,85 \%$ \\
\hline A11 & Kesesuaian tingkat harga penginapan & 1370 & 1519 & $90,19 \%$ \\
\hline A12 & Tersedia lahan parkir yang memadai & 1263 & 1801 & $70,13 \%$ \\
\hline A13 & Keamanan tempat parkir & 1592 & 1873 & $85,00 \%$ \\
\hline A14 & Tersedia jumlah kamar mandi/toilet yang memadai & 1389 & 1869 & $74,32 \%$ \\
\hline A15 & Toilet yang bersih & 1303 & 1857 & $70,17 \%$ \\
\hline A16 & Pengelolaan dan tata letak komponen wisata yang baik & 1279 & 1810 & $70,66 \%$ \\
\hline A17 & $\begin{array}{l}\text { Tersedia tempat sampah yang memadai di kamar } \\
\text { mandi dan sekitar lokasi wisata }\end{array}$ & 1347 & 1770 & $76,10 \%$ \\
\hline A18 & Terdapat rambu-rambu keamanan pada objek wisata & 1192 & 1619 & $73,63 \%$ \\
\hline A19 & Kondisi jalan menuju tempat wisata & 1246 & 1797 & $69,34 \%$ \\
\hline
\end{tabular}

atribut yang perlu ditingkatkan agar kepuasan wisatawan meningkat dan kepuasan dirasakan pada keseluruhan atribut. 


\begin{tabular}{|l|l|c|c|c|}
\hline No & \multicolumn{1}{|c|}{ Indikator } & $\begin{array}{c}\text { Penilaian } \\
\text { Kinerja } \\
(\mathrm{X})\end{array}$ & $\begin{array}{c}\text { Penilaian } \\
\text { Kepentingan } \\
(\mathrm{Y})\end{array}$ & Tki (\%) \\
\hline A20 & Tersedia transportasi umum menuju lokasi wisata & 1379 & 1763 & $78,22 \%$ \\
\hline A21 & $\begin{array}{l}\text { Jumlah transportasi umum yang memadai menuju } \\
\text { lokasi wisata }\end{array}$ & 1286 & 1695 & $75,87 \%$ \\
\hline A22 & Jarak menuju lokasi wisata dari pusat kota & 1420 & 1571 & $90,39 \%$ \\
\hline A23 & Jarak penginapan/hotel dari lokasi wisata & 1429 & 1657 & $86,24 \%$ \\
\hline A24 & Tersedia penunjuk arah menuju lokasi wisata & 1434 & 1785 & $80,34 \%$ \\
\hline A25 & $\begin{array}{l}\text { Terdapat Bank/ATM di sekitar wisata dan araknya } \\
\text { terjangkau }\end{array}$ & 1405 & 1706 & $82,36 \%$ \\
\hline A26 & Keramahtamahan warga sekitar objek wisata & 1478 & 1725 & $85,68 \%$ \\
\hline \multicolumn{2}{|c|}{ Rata-rata } & $\mathbf{8 0 , 1 9 \%}$ & \\
\hline
\end{tabular}

Tabel 7. Urutan Prioritas Perbaikan Atribut Wisata Pemandian di Tapanuli Utara

\begin{tabular}{|c|c|c|c|}
\hline No & Indikator & Tki $(\%)$ & $\begin{array}{l}\text { Rata-Rata } \\
\text { Kesesuaian }\end{array}$ \\
\hline A19 & Kondisi jalan menuju tempat wisata & $69,34 \%$ & \multirow{26}{*}{$80,19 \%$} \\
\hline A12 & Tersedia lahan parkir yang memadai & $70,13 \%$ & \\
\hline A15 & Toilet yang bersih & $70,17 \%$ & \\
\hline A16 & Pengelolaan dan tata letak komponen wisata yang baik & $70,66 \%$ & \\
\hline A4 & Pengelolaan tempat wisata untuk spot foto & $71,01 \%$ & \\
\hline A6 & Pelayanan pegawai restoran/ warung makan/rumah makan & $72,20 \%$ & \\
\hline A18 & Terdapat rambu-rambu keamanan pada objek wisata & $73,63 \%$ & \\
\hline A7 & Cita rasa makanan & $74,03 \%$ & \\
\hline A14 & Tersedia jumlah kamar mandi/toilet yang memadai & $74,32 \%$ & \\
\hline A21 & Jumlah transportasi umum yang memadai menuju lokasi wisata & $75,87 \%$ & \\
\hline A17 & $\begin{array}{l}\text { Tersedia tempat sampah yang memadai di kamar mandi dan } \\
\text { sekitar lokasi wisata }\end{array}$ & $76,10 \%$ & \\
\hline A20 & Tersedia transportasi umum menuju lokasi wisata & $78,22 \%$ & \\
\hline A24 & Tersedia penunjuk arah menuju lokasi wisata & $80,34 \%$ & \\
\hline A5 & Tersedia restoran/warung makan/ rumah makan & $80,67 \%$ & \\
\hline A1 & Keindahan pemandangan alam & $82,16 \%$ & \\
\hline A25 & Terdapat Bank/ATM di sekitar wisata dan araknya terjangkau & $82,36 \%$ & \\
\hline A8 & Kesesuaian tingkat harga makanan & $84,10 \%$ & \\
\hline A13 & Keamanan tempat parkir & $85,00 \%$ & \\
\hline A26 & Keramahtamahan warga sekitar objek wisata & $85,68 \%$ & \\
\hline A23 & Jarak penginapan/hotel dari lokasi wisata & $86,24 \%$ & \\
\hline $\mathrm{A} 2$ & Manfaat kesehatan setelah kunjungan & $87,90 \%$ & \\
\hline A11 & Kesesuaian tingkat harga penginapan & $90,19 \%$ & \\
\hline A22 & Jarak menuju lokasi wisata dari pusat kota & $90,39 \%$ & \\
\hline A3 & Perasaan relaksasi setelah kunjungan & $90,45 \%$ & \\
\hline A10 & Tersedia penginapan/hotel di sekitar lokasi wisata & $91,85 \%$ & \\
\hline A9 & Terdapat toko souvenir/ cenderamata & $91,94 \%$ & \\
\hline
\end{tabular}

b. Pemetaan Atribut menggunakan Diagram Kartesius 


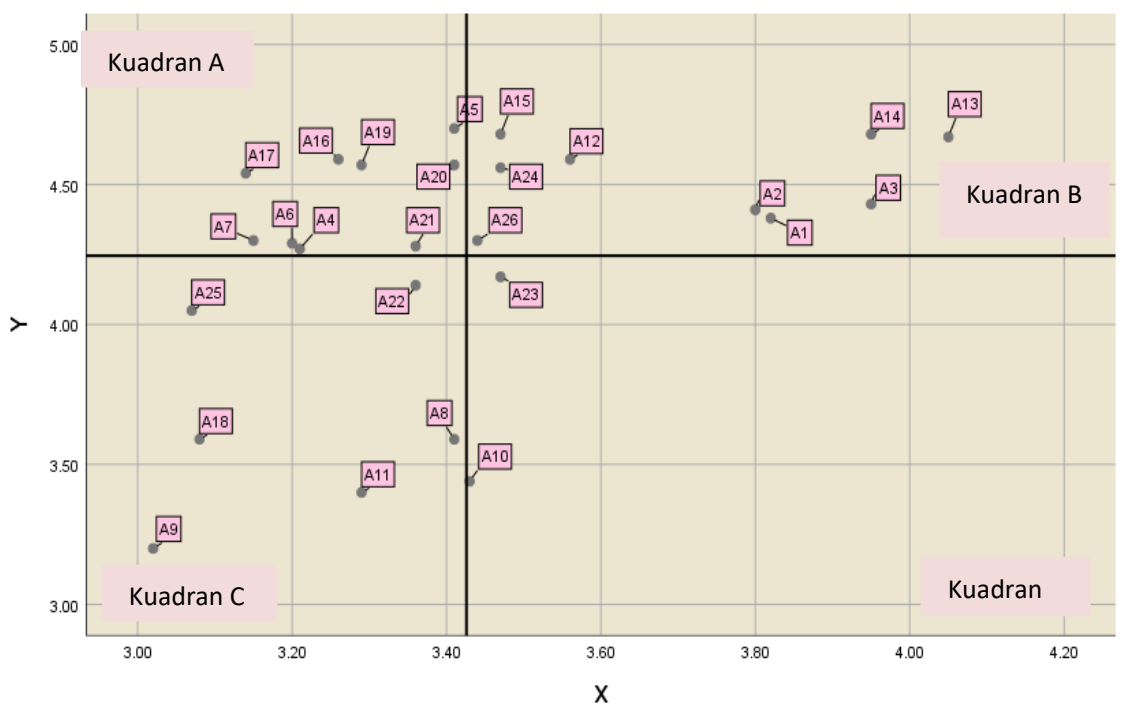

Gambar 8. Diagram Kartesius Atribut Wisata Pemandian Air Panas Sipoholon

\section{KESIMPULAN}

Adapun kesimpulan yang bisa diambil dari penelitian ini adalah:

1. Dalam mengambil keputusan untuk mengunjungi wisata pemandian di Tapanuli Utara, wisatawan cenderung menerapkan tahap keputusan pembelian produk yaitu mengenal kebutuhan kunjungan untuk rekreasi, mencari informasi secara langsung mengenai tanggapan orang lain serta hal menarik mengenai wisata pemandian, mengevaluasi alternatif wisata yang akan dikunjungi hingga akhirnya memutuskan untuk berkunjung dan tanggapan wisatawan untuk ingin kembali berkunjung atau tidak setelah melakukan kunjungannya .

2. Berdasarkan perhitungan tingkat kepuasan menggunakan Customer Satisfaction Index diperoleh nilai kepuasan keseluruhan atribut adalah $68,89 \%$ yang berada pada kategori puas. Meskipun begitu, namun masih terdapat atribut yang dinilai penting tetapi kinerjanya kurang memuaskan sehingga perlu perbaikan agar kepuasan yang dirasakan wisatawan sesuai dengan apa yang diharapkan pada keseluruhan atribut.

3. Berdasarkan perhitungan nilai kepentingan dan performansi pada wisata pemandian di Tapanuli Utara menggunakan metode Importance Performance Analysis (IPA) diperoleh bahwa dari 26 atribut, terdapat 8 atribut yang berada pada kuadran A (prioritas utama) yaitu A4, A6, A7, A12, A15, A16, A17 dan A19. Lalu 9 atribut di pada kuadran $B$ (pertahankan prestasi) yaitu A1, A2, A3, A5, A13, A14, A20, A24 dan A26. Pada kuadran C (prioritas rendah) terdapat 6 atribut yaitu A8, A9, A10, A11, A18 dan A21, Sedangkan pada kuadran D (berlebihan) sebanyak 3 atribut yaitu A22, A23 dan A25.

4. Berdasarkan hasil perhitungan nilai kepentingan dan performansi terhadap ketiga wisata pemandian di Tapanuli Utara menggunakan metode IPA maka diperoleh atribut yang beirisan dari ketiga objek penelitian (memiliki posisi yang sama pada setiap kuadran di diagram kartesius) yaitu pada kuadran A adalah A6, A7, A19, kuadran B A2, A3, A13, A24 dan A26, pada kuadran C tidak ada dan pada kuadran $\mathrm{D}$ yaitu A23. Hasil irisan menunjukkan bahwa atribut yang termasuk di dalamnya merupakan atribut yang memang memiliki kondisi yang sama pada setiap objek yang diteliti sehingga perilaku yang dibutuhkan atribut tersebut harus benar-benar sesuai dengan posisinya pada hasil kuadran irisan. 


\section{DAFTAR PUSTAKA}

Badan Pusat Statistika. (2017). Sumatera

Utara termasuk 11 Destinasi

Wisata Favorit.

Martilla, J. A., \& James, J. C. (1977).

Importance-Performance Analysis.

Journal of Marketing, 41(1), 77-79.

doi: $10.2307 / 1250495$

Pangaribuan, T. (2018). Analisis Kepuasan

Wisatawan dengan Metode

Customer Satisfaction Index dan

Importance Performance Analysis

pada Destinasi Wisata Pantai di

Kawasan Toba Samosir. Laguboti:

Institut Teknologi Del.

Setyanto, L. E., Arifin, Z., \& Sunarti.

(2017). Pengaruh Atribut Produk

terhadap Keputusan Pembelian

(Survei Pembeli Apple iPhone

pada Mahasiswa/Mahasiswi S1

Fakultas Ilmu Administrasi

Program Studi Ilmu Administrasi

Bisnis Angkatan 2013/2014

Universitas Brawijaya Malang).

Jurnal Administrasi Bisnis, 46, 19-

27.

Wicaksono, B. L., Susanto, A., \&

Winarno, W. W. (2012). Evaluasi

Kualitas Layanan Website

Pusdiklat BPK RI menggunakan

Metode Webqual Modifikasian dan

Importance Performance Analysis .

Media Ekonomi \& Teknologi

Informasi, 21-34.

Yoeti, O. (1996). Pengantar Ilmu

Pariwisata. Bandung: Angkasa. 